\title{
In-Situ Heat Release Measurement of Smoldering Combustion of Wood Sawdust
}

\author{
HIDEO OHTANI, TAKESHI MAEJIMA and YOICHI UEHARA \\ Department of Safety Engineering, Faculty of Engineering \\ Yokohama National University \\ 156 Tokiwadai, Hodogaya-ku, Yokohama 240, Japan
}

\begin{abstract}
To evaluate in ${ }^{-}$situ heat release rate of the smoldering combustion, temperature histories in a wood sawdust layer were measured. There were three distinct region in a measured temperature history. They were attributed to the preheat region, the charring region, and the decaying region. Boundaries between those regions were identified on the temperature history as points of inflection. The smoldering front was considered to be the boundary between the preheat and the charring regions. The fact that the temperature history has a point of inflection at the smoldering front means heat release at the front. The heat release rate at the front if incoming and outgoing heat fluxes at the front were evaluated. To evaluate these fluxes, temperature profile in the layer was derived from the temperature histories at several heights and spread rate of the smoldering front, which was constant during a test run. Heat release rate at the smoldering front was estimated from the difference between the incoming and outgoing heat fluxes at the smoldering front. The evaluated heat release rate showed no dependence on the atmospheric oxygen concentration. From the result, the reaction occurred at the smoldering front was considered to be a pyrolysis reaction. However, the activation energy evaluated from the heat release rate was $13.7 \mathrm{~kJ} / \mathrm{mol}$ which is much smaller than usually referred activation energy for wood pyrolysis. Oxygen in atmosphere is considered to work, at least, as a catalyst of the reaction.
\end{abstract}

KEYWORDS: Smoldering, heat release rate, wood, temperature profiles.

\section{INTRODUCTION}

The smoldering combustion of an upholstered chair and so on is one of the major onsets of home fire accidents. In the smoldering combustion a very high amount of toxic gases are produced compared with the flaming combustion. Therefore, many studies have been done to get better information on the smoldering combustion ${ }^{1-4}$. They are indispensable for 
planning safe evacuation from the fire room.

The spreading rate of the reaction zone is, of course, one of the major aspects of the smoldering combustion. The spreading rate is dependent on the heat flow in the same way as the flaming combustion. However, the major part of heat flow is limited to the solid phase in the case of the smoldering combustion. The heat is produced in the reaction zone and transferred mainly to the surrounding solid material. The heat release rate in the reaction zone is one of the dominant factors which controls the spreading rate.

The heat release rate of the smoldering material, e.g. a variety of woods, has been investigated by using thermal analysis methods ${ }^{5-7}$. However, in the real fire condition, the heating condition of the material may be different from that of the thermal analysis method. Surrounding atmosphere may also differ from that of the thermal analysis. Then the heat generation rate in the real fire condition was evaluated in this study by measuring temperature history across the smoldering front.

\section{EXPERIMENTAL PROCEDURE}

As a smoldering material fine grain(0.25-0.5 mm) wood sawdust for explosive uses was used because it smolders easily and is believed to be fairly uniform. The material is said to be a blend of Japanese soft woods. The sample was dried in an electric oven at $110^{\circ} \mathrm{C}$ for 3 hours. Then it was kept in a desiccator at room temperature for over 24 hours before use.

The wood sawdust was laid on the sample stand made by an insulating board $(7 \mathrm{~cm}$ wide $\mathrm{x} 30 \mathrm{~cm}$ long $\mathrm{x} 1 \mathrm{~mm}$ thick). The sample layer was $3 \mathrm{~cm}$ wide, $10 \mathrm{~cm}$ long and $20 \mathrm{~mm}$ thick. The volumetric density of the sample was $0.2 \mathrm{~g} / \mathrm{cm}^{3}$. Two sticks of the insulating material were set along the layer slightly apart from the side faces of the layer to keep the smoldering front flat during an experiment.

The sample stand was placed in a PMMA box as shown in Fig. 1. Air

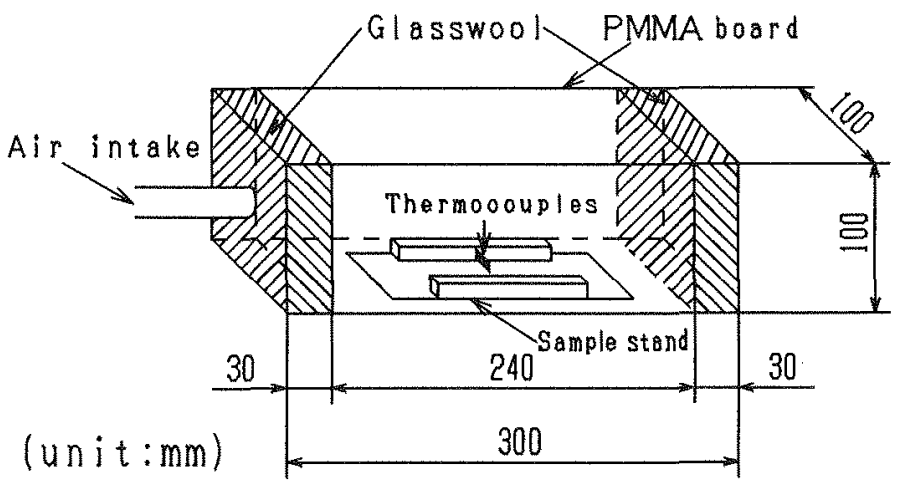

FIGURE 1. Schematic illustration of the experimental apparatus. 
was supplied through the air intake at the Iine speed $8 \mathrm{~cm} / \mathrm{sec}$ in the box. The air speed caused no appreciable effect on the smoldering phenomena up to $2 \mathrm{~m} / \mathrm{sec}$. Nitrogen was added to the supplied air to reduce oxygen concentration. Oxygen concentration in the atmosphere was monitored by an oxygen analyzer(Fujikura FCX-S) just above the sample layer. The observed oxygen concentration was decreased a little when the smoldering front passed the oxygen analyzer. But the observed values at upstream and downstream of the smoldering front showed the identical value. The measured value was used as the oxygen concentration in atmosphere. Glasswool layers were placed at head and tall of the box to keep the laminar flow fleld. In this box the smoke from a joss stick was observed to trail horizontally in a line.

The sample layer was ignited at the downstream or the upstream edge by a pilot flame. The spread rate of the smoldering front seemed to be constant for all experimental runs. Therefore, the spread rate was evaluated from time consumed by the smoldering front moving across 2 points placed $4 \mathrm{~cm}$ apart. Temperature histories of the sample were observed by using $0.08 \mathrm{~mm}$ CA-thermocouples. They were placed $50 \mathrm{~mm}$ downstream from the head of the sample layer and $4,8,12$ and $16 \mathrm{~mm}$ above the bottom of the layer.

\section{EXPERIMENTAL RESULTS AND DISCUSSION}

\section{Spread Rate of the Smoldering Front}

Figure 2 shows the dependence of the spread rate of the smoldering front on the oxygen concentration. The spread rate decreased as the oxygen concentration decreased. The smoldering front could not spread when the oxygen concentration was under about $14.5 \%$. This figure shows the oxygen concentration affect strongly on the smoldering phenomena compared with the layer thickness or the spreading direction.

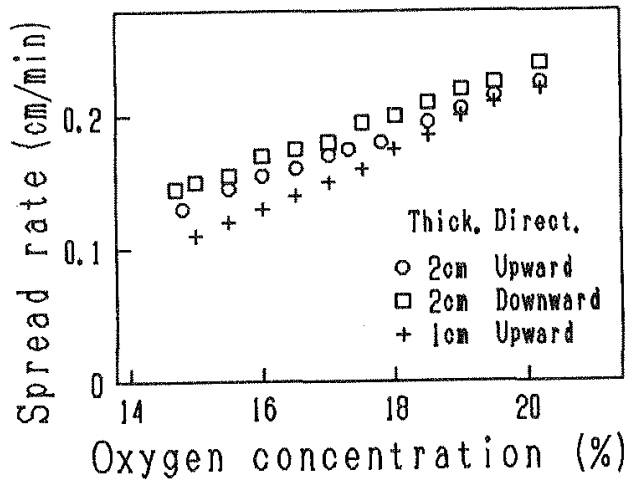

FIGURE 2. Dependence of the smoldering front spread rate on the oxygen concentration 


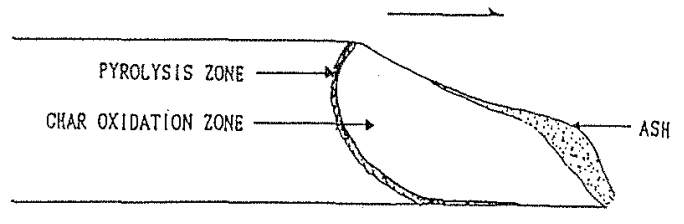

a)

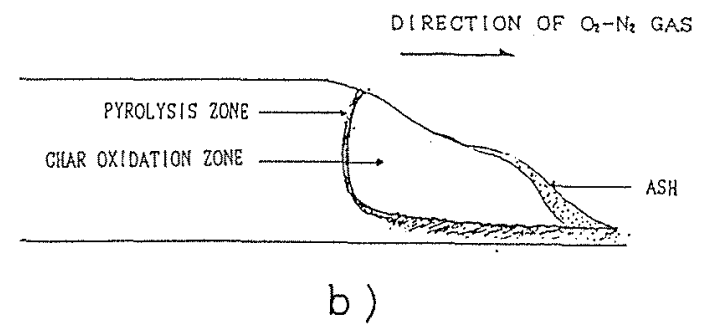

FIGURE 3. Typical aspects of the smoldering front: a) in air, b) in low oxygen atmosphere.

Figure 3 shows the typical aspects of the smoldering front. The smoldering front has a smooth shape in air, but has a steep shape in low oxygen atmosphere. It was considered that the smoldering front at the deep position was driven by an exothermic reaction which was not an oxidizing one. Therefore, the smoldering front spreads at constant rate except in the neighboring area of the bottom plate in low oxygen atmosphere. However, excess oxygen supply in air enhanced the heat release rate near the smoldering front and the smoldering front near the sample layer surface spreaded faster than that in deep area.

\section{Temperature Histories in the Sample Layer}

Figure 4 shows the temperature histories for the smoldering spread in air. Three distinct regions could be identified for each temperature curve by two points of inflection. By comparing the temperature history with observation as shown in Fig. 3, the three regions were attributed to the preheat region, the charring region and the decaying region in the order. The smoldering front was considered to pass the thermocouple at the first point of inflection. The pyrolysis zone in Fig. 3 was not clear in Fig. 4, but it was considered to lie very close to the smoldering front. The first point of inflection is convex and not sharp. Heat release reaction was considered to occur near the smoldering front. The pyrolysis reaction should be the heat release reaction. 


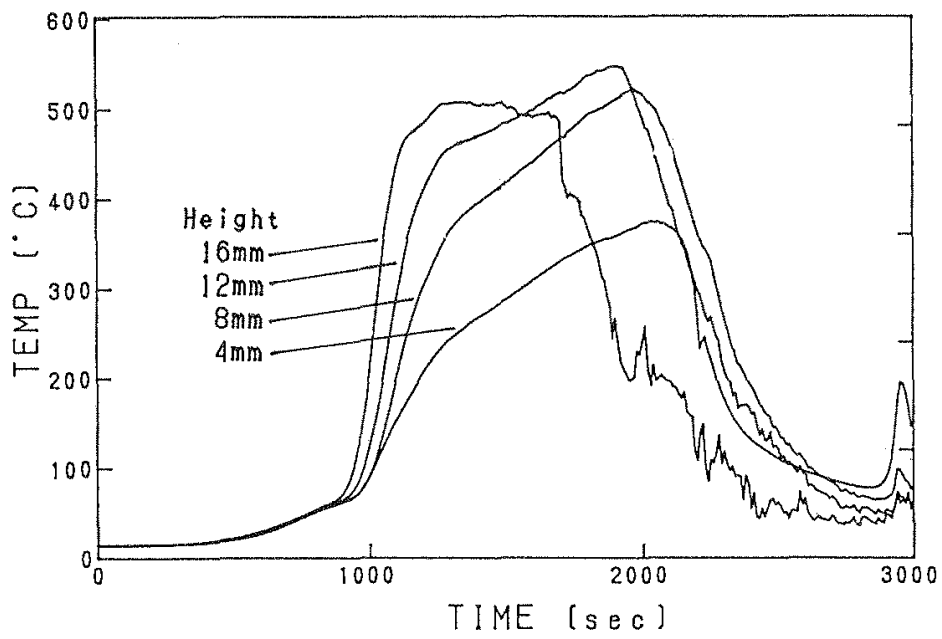

FIGURE 4. Temperature histories in the sample layer for the smoldering spread in air: Thermocouples were placed at $4,8,12$ and $16 \mathrm{~mm}$ above the botton plate.

\section{Temperature Profile in the Sample Layer}

To evaluate the heat flux direction at the smoldering front, the temperature profile in the sample layer was derived from the temperature histories. Figure 5 shows the temperature profile derived from Fig. 4. This figure shows the profile when the smoldering front just passed the location of the highest thermocouple. The origin of the horizontal distance was set at the thermocouple location. Although the temperature history has a distinct point of inflection at the smoldering front, the smoldering front is not clear in Fig. 5. It should be due to the roughness of the temperature profile which was derived from only four temperature histories.

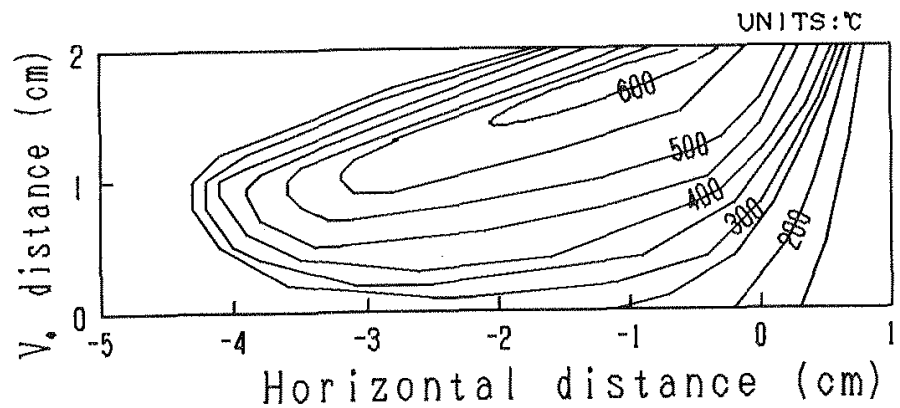

FIGURE 5. Temperature profile in the sample layer for the smoldering spread in air. 


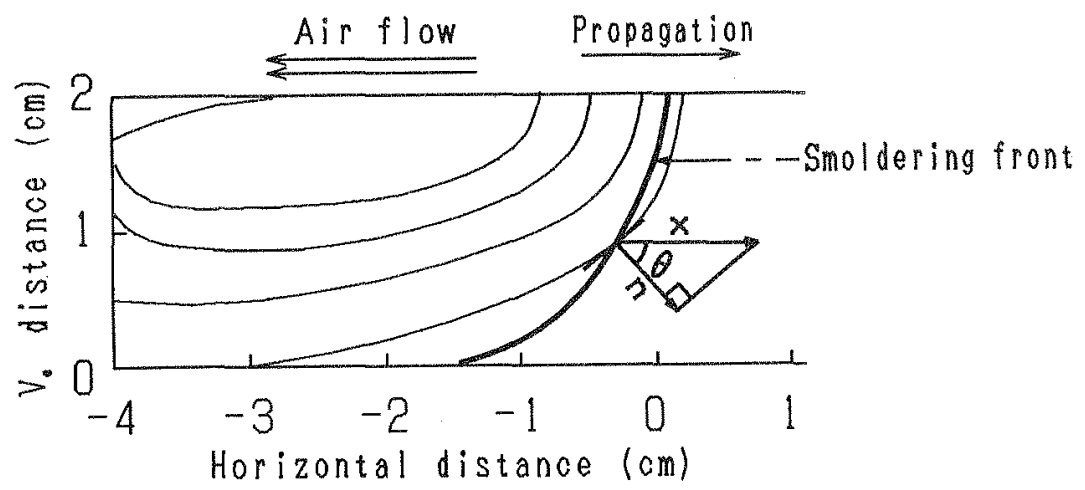

\section{FIGURE 6. Heat flux at the smoldering front}

Figure 6 shows how to evaluate the heat flux direction at the smoldering front. The heat flux is directed normal to an isotherinal contour. Therefore, the heat flux direction can be evaluated from the normal line at the smoldering front.

The heat flux depends on temperature gradient in the heat flux direction. On the other hand, temperature gradient in the horizontal direction can be derived easily from the temperature history shown in Fig. 4. As the heat flux direction is known, the temperature gradient $d \mathrm{~T} / \mathrm{d} \mathrm{n}$ in the heat $\mathrm{flux}$ direction is obtainable by correcting the temperature gradient $\partial \mathrm{T} / \partial \mathrm{x}$ in the horizontal direction. The following equation shows the correction.

$d T / d n=(\partial T / \partial x) / \cos \theta$

Consequently, the heat $f l u x \dot{q}^{\prime \prime}$ can be derived as

$\dot{q}^{\prime \prime}=\lambda(d \mathrm{l} / d \mathrm{n})$.

The thermal conductivity $\lambda(0.00064 \mathrm{~J} / \mathrm{cm} \cdot \mathrm{s} \cdot \mathrm{K})$ was evaluated by using Eq. (6) in Ref. 8 for a dry wood with density $0.2 \mathrm{~g} / \mathrm{cm}^{3}$.

\section{Heat Release Rate along the Smoldering Front}

As easily seen from Fig. 4, the heat flux changed suddenly at the smoldering front. The heat flux $\mathrm{q}^{\prime \prime}$ from the charring region was smaller than the heat flux $\dot{q}_{b}^{\prime \prime}$ to the preheat region. From the difference between them, heat release rate $\dot{q}$ at the smoldering front was estimated as

$\dot{\mathrm{q}}=\dot{\mathrm{q}}_{\mathrm{b}}^{\prime \prime}-\dot{\mathrm{q}}_{\mathrm{a}}^{\prime \prime}$.

The heat release rate should be considered as a total value of the heat release reaction near the smoldering front. 


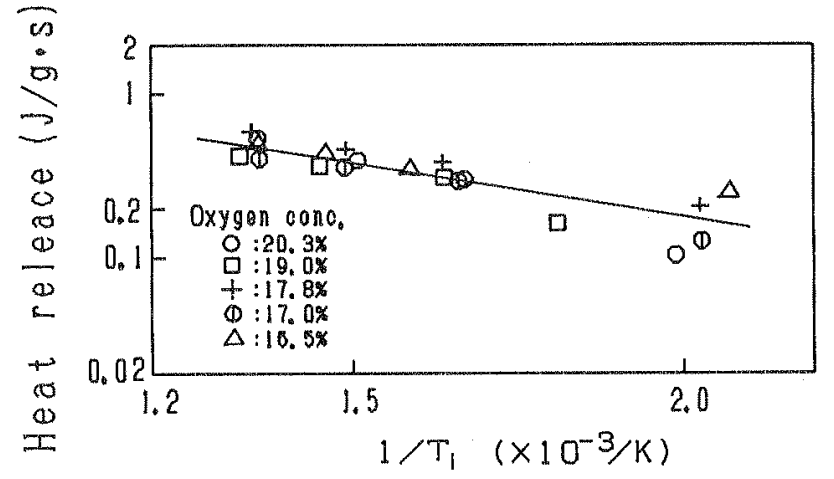

FIGURE 7. Variation of the heat release rate with the smoldering front temperature.

Figure 7 shows the evaluated heat release rates at the smoldering front against the reciprocal of the temperature at the point. No appreciable effect of the oxygen concentration can be seen in this figure. This fact seems to supports the supposition that the pyrolysis reaction occurs near the smoldering front. If this reaction was the pyrolysis reaction and the heat release rate could be expressed as

$\dot{\mathrm{q}}=\mathrm{A} \cdot \mathrm{Q} \cdot \mathrm{P} \exp \left(-\mathrm{E} / \mathrm{RT}_{\mathrm{i}}\right)$.

Here $A, Q, P, E, R$ and $T$, are a constant, the heat of reaction, density, activation energy, the gas constant and the temperature at the point, respectively. By taking a logarithmic transformation. Eq. (4) becomes

$\ln q=\ln (A \cdot Q \cdot P)-E / R_{1}$.

Relation between $\mathrm{q}$ and $\mathrm{T}$, was obtained from Fig. 7 as

$\ln \mathrm{q}=1.50-1650 / \mathrm{T}_{1}$

Hence, by comparing Eq. (5) with Eq. (6), the activation energy was evaluated as $13.7 \mathrm{~kJ} / \mathrm{mol}$. The evaluated activation energy was considerably smaller than that for pyrolysis reaction of wood saw dust(ca. $100 \mathrm{~kJ} / \mathrm{mol}^{\mathrm{B}} \mathrm{l}$.

Although this discrepancy between the evaluated activation energy and that for the wood pyrolysis arose a doubt in the supposition that the heat release reaction was a pyrolysis reaction, the reaction should be a pyrolysis reaction from the fact that the oxygen concentration affect little on the heat release rate. This discrepancy may come from the difference in heating environment which includes heating rate and atmosphere. 


\section{CONCLUSIONS}

The heat release rate at the smoldering front was evaluated from the temperature profile in the real fire condition. The heat release rate depended lineariy on the reciprocal of the temperature at the smoldering front. The activation energy for the heat release reaction was evaluated from the relation between the heat release rate and the smoldering front temperature. The evaluated activation energy was $13.7 \mathrm{~kJ} / \mathrm{mol}$, which was considerably smaller than that for pyrolysis of wood.

\section{Acknowledgement}

The authors wish to express their sincere thank to Mr. T. Ohno for his help in conducting experiments.

\section{REFERENCES}

1. Palmer, K. N., "Smoldering Combustion in Dusts and Fibrous Materials", Combustion and Flame. 1, $129(1957)$.

2. Sato, K. and Sega, S., "Smolder Spread in a Horizontal Layer of Cellulosic Powder". FIRE SAFETY SCIENCE - Proceedings of the second international symposium, pp. 87-96, 1989.

3. Ohlemiller, T. J., "Modeling of Smoldering Combustion Propagation", Progress in Energy and Combustion Sciences, 11. $277(1985)$.

4. Gann, R. G., Harris, R. H., Jr., Krasny, J.F., Levine, R. S., Mitler, H. E., and Ohlemiller, T. J., "The Effect of Cigarette Characteristics on the Ignition of Soft Furnishings", NBSTN 1241, 1988.

5. Roberts, A.F., "The Heat of Reaction During the Pyrolysis of Wood", Combustion and Flame, 17, 79 (1971).

6. Kollmann, F.F.P. and Topf, P., "Exothermic Reactions of Wood at Elevated Temperatures", J. Fire \& Flammability, 2, 231(1971).

7. Havens, J.A., Welker, J.R., and Sliepcevich, C.M., "Pyrolysis of Wood: A Thermoanalytical Study", J. Fire \& Flamability, 2. 321(1971).

8. Kanury, A. M. and Blackshear, P. L., Jr., "Some Considerations Pertaining to the Problem of Wood-Burning", Combustion Science and Technology, 1, 339(1970). 